Revista Kinesis, Santa Maria, v.36, n.1, p. 02-15, jan-abr. 2018 Centro de Educação Física e Desportos - UFSM

DOI: $10.5902 / 2316546429483$

Data de submissão: 06-04-2016

Data de Aceite: 19-03-2018

\section{Revista Kinesis}

\title{
REFLEXÕES DOS FUTUROS PROFESSORES DE EDUCAÇÃO FÍSICA SOBRE O SEU PROCESSO DE FORMAÇÃO ACADÊMICA.
}

\author{
REFLECTIONS OF FUTURE PHYSICAL EDUCATION TEACHERS ABOUT YOUR ACADEMIC \\ BACKGROUND PROCESS. \\ REFLEXIONES DE LOS FUTUROS PROFESORES DE EDUCACIÓN FÍSICA SOBRE SU PROCESO \\ DE FORMACIÓN ACADÉMICA.
}

\author{
Ricardo Jorge Franco Lima \\ ricardo.lima@esdl.ipvc.pt \\ Instituto Politécnico de Viana do Castelo \\ Larissa Cerignoni Benites \\ lari.benites@gmail.com \\ Universidade do Estado de Santa Catarina
}

\author{
Rui Manoel Coelho Resende \\ rresende@ismai.pt \\ Instituto Universitário da Maia
}

Silvia Maria Castro Fortes Cardoso

silviacastrocardoso@hotmail.com

Universidade Nova de Lisboa

\begin{abstract}
RESUMO
Trata-se de uma pesquisa qualitativa com o objetivo de retratar a percepção de cinco professores-estagiários-PE portugueses sobre sua própria formação acadêmica, por meio do grupo focal e a análise de conteúdo. Os resultados demonstraram que os PE sentem a necessidade de um maior contato com a realidade escolar durante a formação acadêmica e que suas dificuldades no estágio dizem respeito ao controle e autoridade da turma ao se trabalhar modalidades que não estavam presentes no plano de estudo. Como consideração final registra-se a presença dos professores supervisor e orientador como fundamentais para o auxílio dos PE e o acontecimento do estágio. Palavras-Chave: Formação de Professores; Educação Física; Estágio Supervisionado; Formação Inicial.
\end{abstract}

\section{ABSTRACT}

This qualitative study is dedicated to see how five future teachers of Physical Education- PE of Portugal understand their own academic training process and the relationship about their practicum experiences. The results showed that PEs feel the need for greater contact with the school reality during the academic formation and that their difficulties in the practicum concern the control and authority of the class when working modalities that were not present in the study plan. As a consideration, the presence of supervisors and supervisors as key to the support of the PE and the internship event is recorded.

Keywords: Teachers Formation; Physical Education; Practicum; Initial Training.

\section{RESUMEN}

Investigación cualitativa con objetivo de retratar la percepción de cinco futuros profesores-PE portugueses sobre su propia formación académica, a través del grupo focal y el análisis de contenido. Los resultados demostraron que los PE sienten la necesidad de un mayor contacto con la realidad escolar durante la formación académica y que sus dificultades se refieren al control y autoridad de la clase al trabajar modalidades que no estaban presentes en el plan de estudio. Como consideración se registra la presencia de los profesores supervisor y orientador como fundamental para ayudar los PE y el acontecimiento de la practica supervisada.

Palabras Clave: Formación de profesores; Educación Física; Practica Supervisada; Formación Inicial. 


\section{Introdução}

A entrada na carreira docente se dá por diferentes processos que acabam por influenciar a opção pela docência, tal como as características pessoais, as experiências socioculturais, os exemplos familiares, o contexto no qual o indivíduo se encontra inserido, a representação enquanto aluno durante os anos escolares, ou seja, fatores que vão delineando caminhos e que acabam por ser potencializados pela formação inicial.

Para o professor de Educação Física não é diferente, e pode-se dizer que no momento em que se inicia o processo formativo, os aspectos advindos da chamada socialização primária (anterior à entrada na Universidade) vão se filiando àqueles atribuídos pela socialização secundária (formação inicial) em termos de mudanças e/ou permanência das crenças, aquisição de um corpo de conhecimento específicos e habilidades que vão consolidar o perfil docente e construir a identidade profissional (TARDIF; LESSARD, 2005). Esse período formativo, faz com que o futuro professor incorpore um corpus da docência, que se dá pela soma da aquisição de diferentes saberes e competências, inclusive pelas experiencias vivenciadas (LOPES; CUNHA, 2007).

Nesse contexto, os estágios acabam por se tornar um lugar interessante, visto, por exemplo, como a primeira entrada profissional, como a passagem de estudantes para professores e que acaba por propiciar um choque entre a realidade da formação acadêmica com a realidade da escola (COSTA FILHO, 2014).

No contexto português, os estágios acontecem de maneira mais incidente no último ano acadêmico, sendo que os futuros professores se assumem como professores estagiários- PE e devem desenvolver um saber-fazer sobre a docência, advindo da confluência entre a teoria a prática (MARTINY; BASTOS NETO; GOMES-DA-SILVA, 2012).

Porém, essa etapa não é isenta de debates e de conflitos que são ocasionados justamente pela justaposição de dois espaços distintos: escola e a universidade (FREIRE; OLIVEIRA, 2004). Sendo assim, investigar os estágios e suas impressões, crenças e reflexões nos pareceu ser providencial para compreender a inter-relação da formação inicial com a inserção profissional.

Dessa forma, o objetivo deste estudo foi apresentar as reflexões dos PE sobre o próprio processo de formação acadêmica, tendo em vista a influência do processo formativo na realização do estágio e nas 
relações travadas com os professores cooperantes e orientadores.

2-Estágio Pedagógico Supervisionado

O estágio pedagógico supervisionado-EPS é o processo final na formação de professores em Portugal. Realizado em um ano, o mesmo marca a transição da universidade para a escola, com todos os sentimentos e ambivalências geradas nesse momento, sendo considerado crucial por entrar em contato com a realidade e ter a responsabilidade e função de professor (ALBUQUERQUE; GRAÇA; JANUARIO, 2005).

Para Pacheco (1995), essa passagem significa uma descontinuidade tripartida da instituição de formação para a escola, de aluno para professor, da teoria para a prática, destacando-se o contexto prático, em que se passará a atuar, como algo forte e marcante no fator de socialização.

Neste sentido, vários estudos apontam o EPS como uma experiência fundamental na formação do futuro professor de Educação Física, sendo que seu objetivo é enriquecer a formação, complementando as aprendizagens acadêmicas com a experiência em locais de exercício profissional e realizar a aproximação da realidade do mundo do trabalho, pensado como uma atividade intrumentalizadora, mas que promove a práxis, permitindo um transitar entre a universidade e escola, vice-versa, de maneira que os envolvidos possam tecer redes de relações, conhecimentos e aprendizagens (PIMENTA; LIMA, 2011; ZABALZA, 2006).

Contudo, aponta-se que o EPS é mais efetivo quando acompanhado por professores experientes. Trata-se então, de um momento diferenciado, pois congrega diferentes perspectivas e envolve agentes que possuem papéis distintos, sendo que esses contribuem de forma decisiva para a imersão na cultura profissional (JONES; STRAKER, 2006; IZA; SOUZA NETO, 2015).

Em Portugal, o EPS conta com o apoio do professor cooperante, que é o professor da escola que recebe e acompanha os PE, assim como do professor orientador, que é o responsável da Instituição de formação inicial pelo processo de estágio.

Neste sentido, a formação do PE de Educação Física no momento do EPS congrega as experiências e conhecimentos disseminados na relação com os alunos da escola, com o professor cooperante e orientador, sendo essa dinâmica importante para a construção da identidade do futuro professor. 


\section{Material e Métodos}

Trata-se de uma pesquisa qualitativa que se utilizou-se da técnica do Grupo Focal que tem como princípio coletar dados em grupos e discutir algo que é proposto pelo pesquisador/ moderador num certo espaço de tempo (GREENBAUM, 2000) com o intuito de obter a perspectiva dos participantes num determinado tópico (ENNIS; CHEN, 2012). Esse processo de Grupo Focal permite ao investigador retirar das entrevistas informações e elementos de reflexão ricos e matizados (ROSADO et al., 2012).

O Grupo Focal deste estudo reuniu cinco PE com idades entre os 22 e 26 anos de uma mesma instituição formadora de professores de Educação Física em Portugal que já tinham realizado o EPS nas escolas. Os participantes foram voluntários na investigação (assinando um consentimento informado) e aceitaram a recolha via áudio dos dados. O local da realização do Grupo Focal foi uma sala de aula da instituição dos PE que assegurou tranquilidade para a sua efetivação.

Para a realização do Grupo Focal, utilizou-se um roteiro, que foi inicialmente construído com base na literatura e de acordo com os objetivos do trabalho. Numa primeira fase, o guião foi objeto de consulta e reformulação por uma equipe de experts em investigação qualitativa. Posteriormente, realizou-se um pré-teste com um Grupo Focal de seis PE (que não fizeram parte do estudo), onde estiveram também presentes os investigadores especialistas em investigação qualitativa. Os dados foram obtidos com a moderação do primeiro autor deste trabalho, que possui vasta experiência na técnica de entrevistas qualitativas, para além do domínio da temática em estudo.

Após esta sessão, houve a reunião e debate do grupo dos investigadores e se propôs ligeiras alterações à sequência das questões do roteiro, assim como, houve a sugestão de apontamentos para a melhoria na moderação do dinamizador do grupo.

Neste sentido, o roteiro foi reformulado nos seguintes enfoques: (1) o percurso acadêmico do futuro professor de Educação Física e (2) o estágio pedagógico supervisionado. Todavia, na realização do roteiro houve a preocupação em se iniciar os questionamentos com as questões abertas, para depois passar para momentos mais objetivos os quais se solicitou exemplos concretos sobre aquilo que era de interesse (RESENDE, 2016). A recolha de dados através da realização do Grupo Focal teve a duração de 108 minutos.

O Grupo Focal foi registrado via áudio e teve suas informações transcritas verbatin existindo a preocupação de, durante a transcrição, construir unidades de significado congruentes com a 
intencionalidade do discurso dos participantes (RESENDE, 2016).

Como ferramenta de análise utilizou-se o software NVIVO 10 para organização e sistematização dos dados adotando alguns elementos da análise do conteúdo (BARDIN, 2009), tal como a pré-análise e a leitura exaustiva organizando o material, seguido da sua exploração, onde se permitiu o encontro das unidades de significados a partir da resposta dos entrevistados, seguida da categorização como operação de classificação de elementos construtivos e o reagrupamento de informações com base nas características dos participantes e no objetivo da pesquisa.

\section{5-Resultados e Discussão}

De forma a obter um enquadramento geral dos dados, foi realizada a organização das informações obtidas por meio da leitura fluente suscitando a discussão dentro da formação inicial dos professores de Educação Física, considerando o domínio e os componentes C1 e C2, que foram pré-estabelecidos no roteiro do Grupo Focal e a proposição de categorias (Ca). É com base nessas informações que os resultados foram apresentados e discutidos.

Quadro 1 - Categorização da análise do Grupo Focal.

\begin{tabular}{ll}
\hline \multicolumn{1}{c}{ Formação de Professores de Educação Física } \\
\hline & $\begin{array}{l}\text { Ca1- Plano de estudos } \\
\mathrm{Ca} \text { - Contato com a realidade escolar } \\
\mathrm{Ca} 3 \text { - Metodologias e objetivos } \\
\mathrm{Ca} \text { - Formação Avaliação na formação acadêmica }\end{array}$ \\
\hline C2 - Estágio Pedagógico Supervisionado & $\begin{array}{l}\mathrm{Ca} \text { - Dificuldades } \\
\mathrm{Ca} \text { - } \text { - Relação com Cooperante e Orientador }\end{array}$ \\
\hline
\end{tabular}

Legenda: Organização da análise dos dados.

Fonte: Dados da pesquisa (construção própria).

\section{Formação Acadêmica}

Esse primeiro apontamento apontou para o percurso acadêmico do PE no ensino superior e, nesse sentido, a categoria Plano de Estudos(Ca1) permitiu compreender a percepção desses futuros professores para com o currículo do curso, assim como a sua aplicabilidade para o exercício da função docente.

Nesse sentido, na fala dos PE aparecem elementos da escolha do curso e que essa incluía a representação de que teriam um maior número de horas de disciplinas orientadas para o ensino. Porém, os PE relatam que durante o curso, houve uma escassa abordagem pedagógica e de didática. 
Tivemos pouca pedagogia e didática. Didática só tivemos no $1^{\circ}$ ano de mestrado . Foi muito pouco e a pedagogia foi muita teoria, não foi no terreno. Acho que nos faltava irmos tendo algum contato com as escolas desde a licenciatura. (PE 4).

A grande lacuna, principalmente nos três primeiros anos, na licenciatura, foi a falta de uma ligação à base daquilo que nós estávamos a estudar, ou seja, uma falta de ensino de como ensinar os alunos. (PE 5).

A situação acima retratada se relaciona à perspectiva do modelo de curso existente, bem como à formatação de divisão entre a licenciatura e o mestrado no contexto português. Os PE alegam que o mestrado acabou sendo uma mais-valia, porém, destacam que seria interessante repensar a maneira como o curso é desenvolvido desde a formação inicial e introduzir unidades curriculares opcionais para que aqueles com interesse na docência pudesse ter maior contato com a realidade escolar e que pudessem adquirir e desenvolver as competências atrelados ao ensino.

Acho pouco relativo isso do contato direto com as crianças ser contínuo nos cinco anos, porque na nossa situação, quando seguimos para o mestrado (não sei se vou estar correto) nós queremos estar com os alunos e era melhor para nós que estivéssemos os cinco anos em contato com eles, mas nem toda a gente que tira a licenciatura quer ir para a via do ensino. (PE 3).

Realmente houve disciplinas que foram bastante boas, disciplinas que abordavam conteúdos basicamente desde a infância até à idade adulta, mas essa vertente mais ligada ao ensino, ao estar em aula com uma turma à frente houve grandes falhas. (PE 4).

Os dizeres dos PE vão ao encontro da literatura, como por exemplo, a crítica posta por Formosinho (2009) ao mencionar que muitos cursos de formação se baseiam em modelos que possuem uma dinâmica da academização e são conduzidos pela lógica da ação tradicional do ensino superior, da demanda de conteúdos a serem transmitidos e acabam sendo fragilizados do ponto de vista da lógica inerente a prática profissional e das aproximações com os fazeres do exercício profissional.

Esse alerta sobre a dinâmica teoria-prática, e sua atenção e preocupação, é algo que vem sendo recorrente na literatura sobre formação de professores (SCHON, 1983; SHULMAN, 1987; FRANCO; 2008; ZEICHNER, 2010; entre outros), como um dos apontamentos para ser constantemente pensado e revisado, uma vez que quando articulada, é sabido que promove melhor desenvolvimento profissional no que tange ao exercício docente (FLORES et al., 2013), sendo assim, torna mais oportuno as experiências e intervenções dos EPS.

De fato, uma das consequências desse tipo de problemática da teoria e da prática distanciada se 
dá justamente na omissão do contato com a realidade escolar; a segunda categoria de análise (Ca2). É no EPS que os PE se dão conta da falta de contato com os alunos das escolas do ensino básico e secundário ao longo da sua formação e percebem a ausência de situações anteriores que os auxiliasse a lidar com as situações reais.

Acho que no nosso percurso temos uma falta de lidar no terreno em si, não temos quase disciplinas nenhumas que apontem diretamente ao terreno, que é aquilo que vamos lidar na nossa profissão e se calhar há muitas disciplinas demasiado teóricas em vez de abordarem a parte mais prática da atividade. (PE 2).

Oliveira (2004), aponta que as disciplinas de intervenção pedagógica possuem grande relevância para os estudantes que pretendem seguir carreira docente, para aqueles que se interessam pelo desenvolvimento motor e físico de seus futuros alunos, bem como para aqueles que visam um bom desenvolvimento profissional.

Esse conjunto de disciplinas pedagógicas, bem como a forma que os professores universitários conduzem suas aulas, apresentam-se como elementos potencializadores de um melhor cenário no que diz respeito às categorias $\mathrm{Ca} 3$ e Ca4.

Nesse sentido, OS PE falam da importância dos professores universitários definirem à priori os objetivos da unidade curricular (UC) e apresentar a metodologia e seus objetivos. Os docentes, na compreensão dos PE, são exemplos e deveriam apresentar uma melhor coerência e consonância no interior da disciplina, mas também entre os próprios professores para que houvesse uma maior aproximação entre eles, bem como dos conteúdos trabalhados, resultando num melhor formato do curso e do processo acadêmico.

Acho importante um professor chegar a uma sala de aula e dizer quais são os objetivos da UC. Muitos davam-nos os programas da disciplina e outros, nada. (PE 4).

Houve professores que na apresentação falavam nos objetivos e houve outros que falavam num dia sobre uma coisa e noutro de outra coisa (PE 1).

Acho que houve muitos professores, que se calhar adotavam uma metodologia que desse mais importância ao que faríamos no terreno, outros, ao que faríamos no plano de aula e isso criava alguma dúvida: o que é que este professor quer? (PE 2).

Dessa forma, além da maneira como os professores conduzem as disciplinas ofertadas pelo curso, os PE também se reportam às formas de avaliações que os mesmos foram sujeitos durante a formação acadêmica. 
Os entrevistados revelam o modo de avaliar seguiu a mesma prerrogativa da metodologia e objetivo, ou seja, cada docente realizou a sua e, para esse grupo de estudantes, talvez devessem ser mais próximas e similares. Sobre esse quesito fazem sugestões, como por exemplo em Didática que poderia, segundo os PE, ter uma avaliação que se relacionasse com a realidade escolar e alterasse a forma que a mesma é realizada (por meio da elaboração de trabalhos de grupo).

Havia diferença entre os professores. Nós como alunos temos um professor, por isso o que sabemos de outro eventualmente poderá ser ouvido e o que é ouvido não é aquilo que se vê, no entanto, parece-me que haviam algumas discrepâncias (no modo de lecionar é natural porque cada professor é único) no modo de avaliar acho que devia ser mais unânime e consistente. (PE 5).

Na parte da avaliação, lembro de didática, que é assim, didática é como haveremos de ensinar alguma coisa. Tivemos essas aulas no terreno, tivemos a abordagem do professor a uma determinada modalidade e como ensinar essa modalidade e depois tivemos uma espécie de um trabalho que... enfim. Acho que isso devia-se ver no terreno a forma como se leciona. (PE 2).

Gonçalves, Albuquerque e Aranha (2008) mencionam que não existe consenso sobre a avaliação, mas o que se evidência nos dizeres dos PE, para além do acordo sobre a forma de se avaliar, está embutida a noção do aprender a avaliar, como uma das responsabilidades que o futuro professor irá enfrentar e terá que tomar decisões a respeito.

Esses apontamentos percebidos e refletidos pelos PE no que diz respeito a metodologia, objetivo e avaliação, destacam, de certa forma, a necessidade de se rever programas, disciplinas do ensino superior, bem como a própria noção de docência dos professores. Acaba por ser um lembrete do compromisso com a docência no ensino superior e que os professores devem prestar atenção nos desafios e entraves do curso (TARDIF; FAUCHER, 2010), no processo de profissionalização e de profissionalidade docente (SILVA, 2011) e no que diz respeito ao manter-se atento a uma formação que seja mais integral para os seus estudantes.

\section{Estágio Pedagógico Supervisionado}

Sobre o EPS, o mesmo foi compreendido como um momento importante no interior do processo de formação inicial e duas categorias foram propostas para a sua análise. A primeira diz respeito as dificuldades sentidas pelos PE (Ca5) e a segunda sobre a relação com os professores cooperantes e supervisores (Ca6). 
A maior dificuldade sentida pelos PE está na passagem de estudante para professor, isto é, quando começam o estágio ainda não se sentem como professores e se sentem distantes da escola.

A minha maior dificuldade foi passar de aluno para professor. A integração na escola, aquela diferença de agora ser professor e não aluno. Ao início foi um bocado difícil. (PE 1).

A maior dificuldade que tive, foi um ligeiro complexo que foi o de conseguir mostrar aos alunos que era professor, porque parecia mais novo do que qualquer aluno da escola. (PE 5).

Acho que não caracterizo como maior dificuldade, mas a minha cooperante estava sempre a dizer que me colocava muito ao nível dos alunos. (PE 3).

Esse constrangimento, registrado pelos PE, é pertinente e cabe discussão sobre a maneira como o processo de formação inicial vem se constituindo. Perrenoud (1995) chamou a atenção para esse enfoque ao mencionar a complexidade das relações envolvidas na formação inicial e a difícil tarefa da aquisição da identidade docente. Em outro enfoque, Cyrino, Benites e Souza Neto (2015), apresentaram as dificuldades dos estagiários sob o ponto de vista dos professores da escola que os recebem e relataram a presença da insegurança na gestão da sala de aula, no agir perante os alunos, no sentir-se professor e no próprio processo de acompanhamento do estágio.

Outras dificuldades sentidas pelos PE dizem respeito aos aspetos administrativos da Educação Física na escola e sobre imprevistos no ensino de modalidades não abordadas no processo de formação acadêmica.

Nunca tinha feito uma ata na minha vida e a orientadora chegou lá e mostrou-nos uma ata igual à do ano passado e nós tínhamos que preencher. Fui para lá sem saber como preencher papéis, do que faz parte do papel do professor. (PE 4).

A minha maior dificuldade foi badminton. Quase que adormecia na aula. Para mim era uma seca. Os alunos a jogar e eu a olhar para o relógio. Depois ter que encontrar exercícios para fazer uma coisa diferente e não saber se resulta... era a maior dificuldade. (PE 1).

Esse cenário, apontou para um dilema de dinâmica de ensino diferenciado, pois na formação inicial muitas vezes é privilegiado os saberes das matérias de ensino, sobre o ensino, mas, por outro lado, na escola muitas vezes o que se privilegia são os saberes a ensinar e as formas do fazer docente. Para os PE, essa perspectiva do domínio do conteúdo, inicialmente, os mesmos acreditaram ser a base para o sucesso na docência, mas com a inserção profissional, vão se dando conta que existem outras exigências (CUNHA; ZANCHET, 2010), que inclusive escapam daquelas que estão no rol das suas proximidades.

Todavia, em contrapartida as inseguranças e desafios, destaca-se o fato de ser fundamental a presença e acompanhamento do estágio, justamente para contrapor esses acontecimentos. Os 
professores, de maneira geral, tanto o orientador como o cooperante, estão em lugares estratégicos para trabalhar com as dificuldades e crises dos estagiários, com os dilemas de autoridade, com as reflexões, com os percalços sobre a indisciplina dos alunos ou mesmo para tratar de questões particulares do ambiente escolar (SANTOS et al., 2008). Esses professores auxiliam na construção da identidade dos futuros professores e realizam um verdadeiro trabalho de mediação (CUNHA; ZANCHET, 2010).

É justamente sobre esses professores que a Ca6 se debruçou, principalmente sobre a relação existente entre a tríade: professores estagiários- professor cooperante- professor orientador. No que diz respeito aos cooperantes, os estagiários registram suas impressões a respeito dos mesmos e do processo de desenvolvimento pedagógico e didático.

Ela era muito exigente, muito, muito, muito e era um bocadinho de luas! (...) A cooperante ao início foi um bocadinho difícil porque nós chegamos do zero. E agora o que faço e o que tenho que fazer? Depois mostrou-se prestável, estava-nos sempre a dizer para não nos esquecermos de fazer as coisas, atenção aos prazos, era muito reflexiva para nós todos. (PE 4).

Se eu tivesse dois anos de estágio seria impecável! Tinha aprendido o dobro, porque o que aprendi no meu ano de estágio, graças ao meu cooperante, das coisas que eu aprendi, a maior parte não veio daqui. (PE1).

Os professores cooperantes possuem importância muito grande para os estagiários em relação ao papel instrumental, instrucional e emocional (ALBUQUERQUE; GRAÇA; JANUARIO, 2005), porém, também enfrentam desafios das condições do exercício dessa função, pois dividem o seu tempo entre ser professor de seus alunos e cooperante dos estagiários.

Contudo, no contexto português esses cooperantes têm sido reconhecidos como figura central dos programas de formação inicial de professores, inclusive, vários são os estudos em que os estagiários apontam o professor cooperante como uma figura ainda mais importante que a do orientador da faculdade.

Em um estudo realizado por Albuquerque, Graça e Januário (2005) sobre as perspetivas dos PE sobre a atuação do cooperante, os mesmos relataram que o cooperante deve ter disponibilidade, competência e amizade em detrimento da exigência e do rigor, percebendo assim a sua importância, não só na transmissão de conhecimentos, mas também na integração do PE com a realidade escolar.

Por sua vez, no que diz respeito à relação do PE com o orientador, quase todos os entrevistados falaram que houve uma ajuda imensa desses professores em relação ao relatório de estágio e ao acompanhamento dessa tarefa. 
Eu mostrava-lhe e se tinha alguma dúvida, marcávamos uma hora, levava para casa e no dia seguinte trazia a correção e, nesse aspecto, sempre disponível...bibliografias e tudo e mais. Ele estava sempre disponível. (PE 4).

Em contrapartida, tive um orientador no relatório científico e eu digo que ele foi o melhor orientador que uma pessoa pode ter. Ele tirava horas de trabalho dele para nos atender a nós e não tinha limite se nós demonstrássemos trabalho, não tinha limite algum para conosco e sempre que nos precisássemos ele ia estar lá. (PE 5).

O orientador, outrora chamado de supervisor, é o elo de ligação da escola com a instituição formadora. A prática orientada, tem como principal objetivo a iniciação à profissão, não devendo ser uma imitação, neste caso do orientador ou mesmo do cooperante, mas sim um espaço de verificação de alternativas possíveis para agir em contexto prático (ALARCÃO, 2007).

As tendências supervisivas devem enquadrar-se no pensamento moderno sobre o ensino, a aprendizagem e a formação, o desenvolvimento profissional, mas também sobre a profissionalidade docente e a cultura das organizações onde está ocorre; a escola. Nesta perspectiva, Oliveira-Formosinho (2002) defende que a supervisão tem que ser encarada fundamentalmente em dois níveis: no da formação, auxiliando no desenvolvimento profissional dos agentes de educação e na sua influência no desenvolvimento e na aprendizagem dos alunos.

\section{Considerações Finais}

Com o objetivo de apresentar algumas reflexões dos PE sobre o próprio processo de formação acadêmica, pode-se dizer que esse processo reflexivo contou com algumas categorias que auxiliaram a elucidar o cenário, principalmente abordando a questão do EPS, que é considerado um momento de crise e faz com que os futuros professores venham a indagar o tipo de formação profissional que vivenciaram.

Nesse sentido, os PE mencionaram aspectos do currículo, ressaltando as lacunas entre a teoria e a prática, bem como práticas existentes entre os docentes da Instituição de formação e o uso de metodologia, objetivos e avaliação que nem sempre dão aos futuros professores suportes em termos de exemplos; não compreendem que esse ‘uso na formação’ não terá o mesmo ‘uso na atuação’.

Outro aspecto evidenciado, diz respeito à necessidade de um maior contato com a realidade escolar por parte dos PE durante a formação acadêmica e, para tal, chama-se atenção para o currículo de formação, no que diz respeito à necessidade em se ter um maior número de unidades curriculares orientadas para a prática pedagógica e didática. 
O EPS é a etapa final da formação do futuro professor de Educação Física em Portugal e, embora os PE desse estudo reportem as suas dificuldades, também ressaltam as contribuições dirigidas ao professor cooperante como o ponto de auxílio na superação de alguns obstáculos, sendo considerado o elemento mais importante no crescimento da identidade profissional do PE.

Já no que diz respeito à relação do PE com o professor orientador, foi considerado como alguém atento ao progresso e crescimento do futuro professor, ajudando-o na elaboração da etapa final do seu percurso acadêmico, neste caso, a elaboração do relatório final de estágio.

Como finalização, fica o registro de que houve a percepção de que é justamente durante o processo de EPS, no choque com a realidade, que os futuros professores passam a revisitar o próprio processo de formação acadêmica e, nesse momento, se dão conta do que obtiveram, aproveitaram ou mesmo ficam aflitos e ansiosos com o que ainda não assimilaram.

O EPS, constitui-se de fato numa oportunidade de vivência da prática profissional, e por essas e outras características, torna-se o período que possibilita pensar sobre a construção da profissão e da identidade profissional.

\section{Referências}

ALARCÃO, I. Formação e supervisão de professores: uma nova abrangência. Revista de Ciências da Educação, Liboa, v. 8, p. 119-128, 2007.

ALBUQUERQUE A.; GRAÇA A.; JANUÁRIO C. Supervisão pedagógica em educação física - a perspetiva do orientador de estágio. Lisboa: Livros Horizonte, 2005.

BARDIN, L. Análise de conteudo. Lisboa: Edições 70, 2009.

COSTA FILHO, R. A. Professores iniciantes de educação física: discussões a partir das fontes de autoeficácia docente. Dissertação (Mestrdo em Ciência da Motricidade)- Universidade Estadual Paulista, Rio Claro, 2014.

CUNHA, M.; ZANCHET, B. M. A problemática dos professores iniciantes: tendência e prática investigativa no espaço universitário. Revista Educação, Porto Alegre, v. 33, n.3, p. 189-197, 2010.

CYRINO, M.; BENITES, L. C.; SOUSA NETO, S. Formação Inicial em Pedagogia: os professores colaboradores no Estágio Supervisionado. Educação Unisinos, São Leopoldo, v.19, n.2, p.252-260, 2015.

ENNIS, C.; CHEN, S. Interviews and focus groups In: ARMOUR, K.; MACDONALD, D. (Eds.), Research methods in physical education and youth sport. London: Routledge, 2012. p. 217-236.

FLORES, P. P. et al. Refletindo sobre o ensino superior: a proposta de docência orientada na perceção dos estudantes da licenciatura em Educação Física. Revista Mackenzie de Educacao Fisica e Esporte, São Paulo, v. 12, n. 1, p. 235-253, 2013. 
FORMOSINHO J. Academização da formação de professores. In: FORMOSINHO, J. (Coord.). Formação de professores: aprendizagem profissional e acção docente. Porto: Porto Editora, 2009. p. 73-92.

FRANCO, M. A. S. Entre a lógica da formação e a lógica das práticas: a mediação dos saberes pedagógicos. Educação e Pesquisa, São Paulo, v.34, n.1, p. 109-126, jan./abr. 2008.

FREIRE, E.; OLIVEIRA, D. Educação Física no ensino fundamental: identificando o conhecimento de natureza conceitual, procedimental e atitudinal. Revista Motriz, Rio Claro, v.10, n.3, p. 140-151, 2004.

GONÇALVES, F.; ALBUQUERQUE, A.; ARANHA, A. Avaliação: um caminho para o sucesso no processo de ensino e de aprendizagem. Maia: Edições Ismai; 2008.

GREENBAUM, T. Moderating focus groups: a pratical guide for group facilitation: Thousand Oaks: Sage Publications, 2000.

IZA, D. F. V.; SOUZA NETO, S. Os desafios do estágio curricular supervisionado em educação física na parceria entre universidade e Escola. Movimento, Porto Alegre, v. 21, n. 1, p. 111-114, 2015.

JONES, M.; STRAKER, K. What informs mentors' practice when working with trainees and newly qualified teachers? Journal of Education for Teaching for International research and pedagogy, London, v.32, n. 2, p. 165-184, 2004.

LOPES, R.; CUNHA A. C. A Educação Física no Ensino Secundário: estudo das representações e atitudes dos alunos. 2007. Disponivel em: http://repositorium.sdum.uminho.pt/handle/1822/21287. Acesso em 14 jul, 2014.

MARTINY, L. E.; BASTOS NETO, J.; GOMES-DA-SILVA, P. N. Diários de aula no estágio supervisionado: análise das propostas pedagógicas da educação física. Revista Mackenzie de Educação Física e Esporte, São Paulo, v. 11, n.1, p. 31-43, 2012.

OLIVEIRA, F. Docência Orientada: aprendizagens compartilhadas no ensino universitário. Revista Olhar Professor, v.7, n.1, p.147-158, 2004.

OLIVEIRA-FORMOSINHO, J. A supervisão na formação de professores I. Da sala à escola. Porto: Porto Editora, 2002.

PACHECO, J. A. Formação de Professores: teoria e praxis. Braga: Instituto de Educação e Psicologia, 1995. PERRENOUD, P. Oficio de aluno e sentido do trabalho escolar. Porto: Porto editora, 1995.

PIMENTA, S. G.; LIMA, M. S. L. Estágio e docência. São paulo: Cortez, 2011.

RESENDE, R. Técnica de Investigação Qualitativa: ETCI. Journal of Sport Pedagogy and Research. Porto, V.2, n. 1, p. 50-57, 2016.

ROSADO, A. et al. Métodos e técnicas de investigação qualitativa. Cruz-Quebrada: FMH edições, 2012.

SANTOS, I. et al. As percepções e os significados para os estagiários de Educação Física em relação à indisciplina na escola. Movimento, Porto Alegre, v.14, n.3, p.117-137, 2008.

SCHÖN, Donald. The Reflective Practitioner. Londres: Temple Smith, 1983.

SHULMAN, Lee. Knowledge and teaching: foundations of a new reform. Harvard Educational Review, Cambridge, v. 57, n.1, p.1-22, 1987. 
SILVA, E. Variação do repertório experiencial do estudante durante a prática de ensino supervisionada da Educação Física e Desporto. (Tese de Doutoramento), Universidade Portucalense Infante D. Henrique, Porto, 2011.

TARDIF, J.; FAUCHER, C. Um pólo de excelência. Caminhos para a avaliação do desempenho docente. In: ALVES, M. P.; MACHADO, E. (Eds.). Um conjunto de balizas para a avaliação da profissionalidade dos professores. Porto: Areal Editores, 2010. p. 32-53.

TARDIF, M.; LESSARD, C. O trabalho docente. Elementos para uma teoria da docência como profissão de interações humanas. Petropólis: Vozes, 2005.

ZABALZA, M. El Practicum y la formación del professorado: Balance y propuesta para las nuevas titulaciones. In: ESCUEDERO, J. M. (Ed.). La mejora de la educación y la formácion del professorado políticas y prácticas.Barcelona: Octaedro, 2006. p. 309-330.

ZEICHNER, K. M. Repensando as conexões entre a formação na Universidade e as experiências de campo na formação de professores em faculdades e Universidades. Revista Educação. Santa Maria, v.35, n. 3, p.479-504, 2010. 